DOI 10.15393/j9.art.2014.759

Анастасия Сергеевна Корнеенко

магистрант кафедры русской литературы и журналистики, филологический факультет, Петрозаводский государственный университет (Петрозаводск, Российская Федераиия) lis0vskaa@yandex.ru

\title{
КОНЦЕПТ «ИСТИНА» В РОМАНЕ М. А. БУЛГАКОВА «МАСТЕР И МАРГАРИТА»
}

Аннотация. Предметом исследования стал концепт «истина» в романе М. А. Булгакова «Мастер и Маргарита».

Целью исследования было провести сравнительный анализ трех редакций романа и выяснить, какими семантическими смыслами оперирует Булгаков в том или ином случае и как это влияет на трансформацию идеи романа от редакции к редакции.

Материалом исследования послужили три редакций романа: первая - «Копыто инженера» (1930-1932), вторая - «Великий канцлер» (1932-1934) и итоговый вариант «Мастер и Маргарита». В трех редакциях Иешуа вовлекает всех, с кем общается, в диалог. В редакциях «Копыто инженера» и «Великий канцлер» М. Булгаков употребляет концепт «истина» в научно-философском и сакральном смыслах. В окончательном тексте романа Иешуа предстал философом, который пребывает в поиске Истины.

Ключевые слова: концепт, истина, М.А. Булгаков, роман «Мастер и Маргарита», Евангелие

K

онцепт «истина» является ключевым в романе Булгакова «Мастер и Маргарита», он присутствует во всех основных редакциях романа (их сравнительный анализ дан в работах М. О. Чудаковой [14], Г. А. Лесскис [4], В. Лосева [6], [7] И. Е. Ерыкаловой [2], Б. В. Соколова [8], [9], [10], [11], [12]), в том числе в редакциях «Копыто инженера»", «Великий канцлер» ${ }^{2}$ и в окончательном тексте романа «Мастер и Маргарита» ${ }^{3}$.

Проблема истины в романе актуализирована в диалоге Пилата и Иешуа. Он восходит к известному эпизоду Евангелия от Иоанна:

Пилат сказал Ему: итак Ты Царь? Иисус отвечал: ты говоришь, что Я Царь. Я на то родился и на то пришел в мир, чтобы свиде- 
тельствовать об истине; всякий, кто от истины, слушает гласа Моего.

Пилат сказал Ему: что есть истина? И, сказав это, опять вышел к Иудеям и сказал им: я никакой вины не нахожу в Нем (Ин. 18:3738).

В редакции 1930-1932 годов «Копыто инженера» Пилат задает евангельский вопрос: «Что есть истина?». Получив ответ: «Истина в том, что у тебя болит голова» (К. и., 218), - он не удовлетворен: «Такую истину и я могу сообщить» (К. и., 218). Только услышав пророчество Иешуа («В этот день тебе нельзя быть с больной головой») (К. и., 219), Пилат проявляет интерес к собеседнику. Иешуа предлагает игемону: «Я буду учить тебя истине» (К. и., 219). Возникает вопрос, какой истине он собирается учить.

В этой редакции Иешуа называют «Иисусом», «Отцом Истины», «Иисусом Назареем» (К. и., 223). Такие наименования отсылают к евангельской традиции. Однако ни разу герой не назван Иисусом Христом. В «Копыте инженера» и в «Beликом канцлере» разбойника Вар-раввана называют Иисусом: имя становится «узнаваемым».

В редакции «Копыто инженера» евангельские именования (хоть и профанно введенное: «Слушай ты, царь истины» (К. и., 222) и всезнание Иешуа контрастируют с его сниженными портретными и речевыми характеристиками. («Иешуа шмыгнул высыхающим носом и вдруг такое проговорил по-гречески, заикаясь» (К. и., 218).

Пародийное изображение героя в этой редакции вызвано тем, что ершалаимская история дана с точки зрения Воланда. Ни Мастера, ни романа еще нет, а есть «Евангелие от сатаны» (К. и., 216).

В редакции 1932-1934 годов «Великий канцлер» вопрос Пилата уточнен: «Что такое истина?» (В. к., 111). Эта форма вопроса остается неизменной и в итоговом тексте. Е.А. Яблоков считает, что форма вопроса меняет содержание. «Пилат акцентирует сущность истины как гносеологической категории» $[15,416]$. Это определение истины вызывает интерес Пилата, как и пророчество Иешуа о последствиях «пребывания на балконе» для игемона. 
Концепт «истина» в романе М. А. Булгакова «Мастер и Маргарита» 483

В итоговой редакции «Мастера и Маргариты» (как и в «Копыте инженера» и «Великом канцлере») Иешуа отвечает на все вопросы Пилата.

В Евангелии Иисус ничего не объясняет и преимущественно молчит. Христа бьют, издеваются, «советуют» ему спасти себя, если он Сын Божий. Всё это евангельский Иисус переносит молча, Он знает, что Его казнят, и добровольно приемлет страдание и смерть как искупительную жертву, в которой заключен ответ на вопрос «что есть истина».

И когда обвиняли Его первосвященники и старейшины, Он ничего не отвечал (Мф. 27:12).

Га-Ноцри пытается вовлечь Пилата в диалог, диспут. С нашей точки зрения, в поведении Иешуа проявляется античная модель диалога-спора, в котором формируется истина. Евангельская формула «молчания-знания» заменена Булгаковым на античную формулу «диалога-поиска».

В «Мастере и Маргарите» Иешуа рационально объясняет головную боль:

Истина, прежде всего в том, что у тебя болит голова $<\ldots$. Это очень просто <...> ты водил рукой по воздуху <...> как будто хотел погладить (IX, 26).

М. М. Дунаев так прокомментировал этот эпизод: «Мудрец-проповедник на поверку оказался средней руки экстрасенсом (выразимся по-современному). И нет никакой скрытой глубины за теми словами, никакого потаенного смысла, который заключался даже в молчании истинного Сына Божия. А тут - истина оказалась сведенной к тому незамысловатому факту, что у кого-то в данный момент болит голова» $[1,149]$.

Трактовка М.М. Дунаева определяет изменение формы вопроса, но не прослеживает трансформацию евангельского сюжета. Из романа исключены все события и атрибуты, свидетельствующие о богочеловеческой природе Христа: Тайная Вечеря, Моление в Гефсиманском саду, обращение к Отцу на Кресте, Воскресение. Нарушая хронологию событий, автор через допрос у Пилата включает в сюжет ряд сцен, заимствованных из Евангелий. Булгаков переносит в священное 
для христианской истории место - Гефсиманский сад убийство Иуды, изображая не Христовы Страсти, а человеческие, вводя таким образом, сюжет возмездия. Вместо евангельского Христа Булгаков создает образ литературного героя.

В ответе Иешуа нет «потаенного смысла», ведь «божественным ведением обладает Пророк» ${ }^{4}$, а земной человек может только духовно приобщиться к сакральной истине, но не обладать ею.

Автор «переписывает» слова Иисуса об истине, не оставляя даже намека на «божественное» знание Иешуа. Его суждение истины не выходит за рамки философского диспута. Если в редакции «Копыто инженера» Пилат лишь однажды называет Иешуа философом, то в итоговой редакции это именование прочно закрепляется за героем. («<... тебе, философ, не пришлось бы разговаривать с Крысобоем»; «Она была такова: игемон разобрал дело бродячего философа»; «Бродячий философ оказался душевнобольным») (IX, 28).

Иешуа остается философом и, не обладая высшей истиной, ищет ее. Га-Ноцри говорит о царстве истины, в которое перейдет человек, что отсылает нас к ветхозаветной и евангельской традициям. «И седьмой Ангел вострубил, и раздались на небе громкие голоса, говорящие: царство мира соделалось царством Господа нашего и Христа Его, и будет царствовать во веки веков» (Откр. 11:15). «Будет называться Иерусалим городом истины» (Зах. 8:3). «Истина возникнет из земли, и правда приникнет с небес» (Пс. 84:12).

Евангельская истина «становится практически синонимом богословия, Слова Божия, не искаженного ложными учениями. В этом смысле истина является основанием Христианской церкви» (Т. Б., 332). В результате вовлечения концепта «истина» в сферу религии «происходит сближение правды и истины в Боге» $[5,191]$. С.А. Лишаев определяет, что «это привело к усвоению первой (правдой) высшего онтологического достоинства Божественного Бытия и усвоению второй (истиной) значения безусловного установления, образца поведения (Христос-Истина есть Солнце Правды для верующего)» $[5,193]$. 
Концепт «истина» в романе М. А. Булгакова «Мастер и Маргарита» 485

Булгаков не развивает рассуждения Иешуа о царстве истины. Автор акцентирует внимание на "”ысокоморальной" личности Иешуа» $[15,419]$, выстраивающего этические модели (в разной мере соприкасающиеся с Евангелием), через которые пытается приобщиться к Истине.

В итоговой редакции речь об истине заходит и в Московских главах («Сон Никанора Ивановича»). В отличие от ершалаимской истории здесь повествователь и герои говорят об истине в несерьезной, игровой обстановке: обманутому нечистой силой взяточнику снится, что он участвует в театральном представлении.

Истина во сне Никанора Ивановича выступает в качестве оппозиции «правда - ложь», сама оппозиция обозначена ситуативно:

Поймите, что язык может скрыть истину, а глаза - никогда! Вам задают внезапный вопрос, вы даже не вздрагиваете, в одну секунду овладеваете собой и знаете, что нужно сказать, чтобы укрыть истину, и весьма убедительно говорите, и ни одна складка на вашем лице не шевельнется, но, увы, встревоженная вопросом истина со дна души на мгновение прыгает в глаза, и все кончено (IX, 309).

С.А. Лишаев, сравнивая толкования истины в словарях С. И. Ожегова, Н. Ю. Шведовой и В.И. Даля, обнаружил «расхождения в словарной сочетаемости» $[5,175]$. «Расхождения обнаруживают следующее: слово “правда" используется в русском языке для обозначения того, в каком отношении к высказыванию о действительности находится говорящий: сказывает ли он то, что на самом деле думает о том или ином предмете, или же он что-то скрывает и вводит собеседника в заблуждение. Слово “истина”, напротив, указывает на то, в каком отношении к истине-как-действительности находится говорящий» $[5,176]$.

Следуя языковой логике, лексема «истина» в Московских главах должна быть заменена на «правду». Булгаков нивелирует и философские, и евангельские связки понятия «истина», которые «работают» в ершалаимских главах.

Смысловой центр - Ершалаим, а в Московских через повествователя - под сомнение ставится истинность Евангелия. 
Употребление концепта «истина» в редакциях «Копыто инженера» и «Великий канцлер» основано на сакрализации и десакрализации истины. В итоговой редакции Иешуа это философ, обладающий ограниченным земным знанием, его напряженный духовный поиск символизирует «вечный путь человечества к Истине» $[15,422]$.

\section{Примечания}

Исследование выполнено в рамках государственного задания Минобрнауки России (ГБТ N 651-14).

1 Булгаков М.А. Копыто инженера. М.: АСТ: Астрель, 2007. 570 с. Далее цитаты даются по этому изданию с сокращением (К. и.) и указанием страницы.

2 Булгаков М.А. Великий канцлер. М.: Новости, 1992. 544 с. Далее цитаты даются по этому изданию с сокращением (В. к.) и указанием страницы.

3 Булгаков М.А. Собр. соч.: В 10 т. М.: Голос, 1999. Т. 9. Мастер и Маргарита. 608 с. Далее цитаты даются по этому изданию с указанием тома и страницы.

4 Толковая Библия или комментарии на все книги Священного Писания Ветхого и Нового Завета: [в 3 кн.]. Стокгольм: Ин-т перевода Библии. Репринт. изд., 1987. Кн. 1. С. 125. Далее цитаты даются по этому изданию с сокращением (Т. Б.) и указанием страницы.

\section{Список литературы}

1. Дунаев М. М. «Истина в том, что болит голова» // Златоуст. 1991. № 1. C. $310-316$.

2. Ерыкалова И.Е. Фантастика Булгакова: Творческая история. Текстология. Литературный контекст. СПб.: Изд-во СПбГУП, 2007. 284 с.

3. Есин А.Б. Принципы и приемы анализа литературного произведения: Учебное пособие: для студентов и преподавателей филологических факультетов, учителей-словесников. М.: Флинта, Наука, 2010. $248 \mathrm{c}$.

4. Лесскис Г.А. Триптих М. Булгакова о русской революции. М.: ОГИ, 1999. $432 \mathrm{c}$.

5. Лишаев С. А. «Правда» и «истина» (языковая концептуализация мира и тематическое своеобразие русской философии) // Вестник Самар. гуманитарной акад. Серия «Философия. Филология». 2006. № 1 (4). C. 173-209. 
6. Лосев В. Живой М. А. Булгаков // Слово, 2000. № 4. С. 76-78.

7. Лосев В. Рукописи не горят // Булгаков М.А. Великий канцлер. М.: Новости, 1992. С. 3-23.

8. Соколов Б. В. М.А. Булгаков: загадки творчества. М.: Дрофа, 2005. $322 \mathrm{c}$.

9. Соколов Б. В.М. Булгаков. Мастер и Маргарита. Очерки творческой истории. М.: Наука, 1991. 176 с.

10. Соколов Б. Расшифрованный Булгаков. Тайна «Мастера и Маргариты». М.: Яуза, Эксмо, 2006. 608 с.

11. Соколов Б. В. Три жизни Михаила Булгакова. М.: Эллис Лак, 1997. $432 \mathrm{c}$.

12. Соколов Б. В. Булгаковская Энциклопедия. М.: Локид-миф, 2000. $592 \mathrm{c}$.

13. Степанов Ю. С. Константы. Словарь русской культуры. Опыт исследования. М.: Школа «Языки русской культуры», 1996. 288 с.

14. Чудакова М. О. Творческая судьба романа М.А. Булгакова «Мастер и Маргарита» // Вопросы литературы. 1976. № 1. С. 218-254.

15. Яблоков Е.А. Художественный мир Михаила Булгакова. М.: Языки славянской культуры, 2001. 424 с.

\section{Anastasiya Sergeevna Korneenko}

Master's Degree Student in Russian Literature and Journalism, the 1st year of training, Faculty of Philology,

Petrozavodsk State University

(Petrozavodsk, Russian Federation) lis0vskaa@yandex.ru

\section{CONCEPT OF "TRUTH" IN THE NOVEL OF MIKHAIL BULGAKOV'S MASTER AND MARGARITA}

Abstract: The subject of our study was the concept of "truth" in Bulgakov's novel Master and Margarita. S. Stepanov gave the definition of a concept. The concept is like a clot of culture in human consciousness; that is the manner, in which culture becomes a part of the mental world of a man. And, on the other hand, the concept is a way for a man as an ordinary, normal person, not a "creator of cultural values" to be included in the culture, and in some cases, to affects it. In the analysis of the concept of "truth" we start from its cultural-and-etymological understanding of the word "truth".

The aim of the study was to conduct a comparative analysis of the three editions of the novel and to find out what semantic meanings Bulgakov deals with in a particular case and how it affects the transformation of the idea of the novel from edition to edition. 
Three editions of the novel were the material for the research: the first is "Engineer Hoof " (1930-1932), the second is Grand Chancellor (1932-1934) and the final version of "The Master and Margarita." In these three editions Yeshua involves everyone who he is talking to in the dialogue. In the editions Engineer Hoof and Grand Chancellor M. A. Bulgakov uses the concept of "truth" in scientific- philosophical and sacred meanings (plans). In the final text Yeshua appears as a philosopher who is in search of the truth.

Keywords: concept, the truth, Bulgakov's novel Master and Margarita, Gospel

\section{References}

1. Dunaev M. M. «Istina v tom, chto bolit golova» ["The Truth is That One Has a Headache"]. Zlatoust [Zlatoust], 1991, no. 1, pp. 310-316.

2. Erykalova I. E. Fantastika Bulgakova: Tvorcheskaya istoriya. Tekstologiya. Literaturnyy kontekst [Fiction of Bulgakov: Creative History. Textual Criticism. Literary Context]. St. Petersburg, Saint-Petersburg University of the Humanities and Social Sciences Publ., 2007. 284 p.

3. Esin A. B. Printsipy i priemy analiza literaturnogo proizvedeniya [Principles and Methods of Analysis of a Literary Work]. Moscow, Flinta, Nauka Publ., 2010. 248 p.

4. Lesskis G. A. Triptikh M. Bulgakova o russkoy revolyutsii [M. Bulgakov's Triptych about the Russian Revolution]. Moscow, OGI Publ., 1999. 432 p.

5. Lishaev S. A. «Pravda» i «istina» (yazykovaya kontseptualizatsiya mira i tematicheskoe svoeobrazie russkoi filosofii) ["Truth" and "Truthfulness" (Linguistic Conceptualization of the World and Thematic Originality of Russian Philosophy)]. Vestnik Samarskoy gumanitarnoy akademii. Ser.: Filosofiya. Filologiya [Bulletin of the Samara Academy of Humanities. Ser.: Philosophy. Philology], 2006, no. 1 (4), pp. 173-209.

6. Losev V. Zhivoy M. A. Bulgakov [Living M. A. Bulgakov]. Slovo [Word]. 2000, no. 4, pp. 76-78.

7. Losev V. Rukopisi ne goryat [Manuscripts Do Not Burn]. M. A. Bulgakov. Velikiy kantsler [M. A. Bulgakov. The Grand Chancellor]. Moscow, Novosti Publ., 1992, pp. 3-23.

8. Sokolov B. V. M. A. Bulgakov: zagadki tvorchestva [M. A. Bulgakov: Mysteries of Creativity]. Moscow, Drofa Publ., 2005. 322 p.

9. Sokolov B. V. Mikhail Bulgakov. Master i Margarita. Ocherki tvorcheskoy istorii [Mikhail Bulgakov. The Master and Margarita. Essays Creative Stories]. Moscow, Nauka Publ., 1991. 176 p.

10. Sokolov B. Rasshifrovannyy Bulgakov. Tayna "Mastera i Margarity» [Decoded Bulgakov. Mystery of The Master and Margarita]. Moscow, Yauza, Eksmo Publ., 2006. 608 p. 
11. Sokolov B.V. Tri zhizni Mikhaila Bulgakova [Three lives of Mikhail Bulgakov]. Moscow, Ellis Lak Publ., 1997. 432 p.

12. Sokolov B.V. Entsiklopediya Bulgakovskaya [Encyclopedia of Bulgakov]. Moscow, Lokid-mif Publ., 2000. 592 p.

13. Stepanov Yu. S. Konstanty. Slovar' russkoy kul'tury. Opyt issledovaniya [Constants. Dictionary of Russian Culture. Research Experience]. Moscow, Yazyki russkoy kul'tury Publ., 1996. 288 p.

14. Chudakova M.O. Tvorcheskaya sud'ba romana M. A. Bulgakova "Master i Margarita" [Creative Destiny of the Bulgakov's Novel "The Master and Margarita"]. Voprosy literatury [Questions of literature]. 1976, no. 1, pp. 218-25.

15. Yablokov E. A. Khudozhestvennyy mir Mikhaila Bulgakova [Art World of Mikhail Bulgakov]. Moscow, Yazyki slavyanskoy kul'tury Publ., 2001. $424 \mathrm{p}$. 